NASA Technical Memorandum 106707

49046

ICOMP-94-18; AIAA-94-2965

\title{
A Fully Implicit Time Accurate Method for Hypersonic Combustion: Application to Shock-Induced Combustion Instability
}

Shaye Yungster

Institute for Computational Mechanics in Propulsion

Lewis Research Center

Cleveland, Ohio

and

Krishnan Radhakrishnan

NYMA, Inc.

Engineering Services Division

Brook Park, Ohio

Prepared for the

30th Joint Propulsion Conference

cosponsored by AIAA, ASME, SAE, and ASEE

Indianapolis, Indiana, June 27-29, 1994

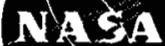

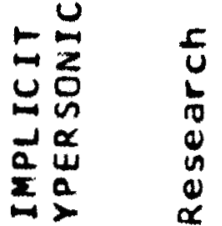

$>x$

$\perp x^{\prime} \geq$

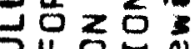

正电舟

O

$<0<3$.

I

14

늘 a

0 a

Nw\&是a

$\varphi=4$

$0 \varangle \# U>0$

$\rightarrow \simeq z \supset$

$1500=$

$2 \cup=Z \pm$

幽舟?

$\frac{1}{4} \cong \pm \frac{1}{2}$

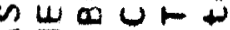

$4 \sum \sum 0$ in

$z=0 I z u$

$$
\text { (1) }
$$




\title{
A Fully Implicit Time Accurate Method for Hypersonic Combustion: Application to Shock-Induced Combustion Instability
}

\author{
Shaye Yungster \\ Institute for Computational Mechanics in Propulsion \\ NASA Lewis Research Center, Cleveland, OH 44135 \\ and \\ Krishnan Radhakrishnan \\ NYMA, Inc. \\ NASA Lewis Research Center, Cleveland, OH 44135
}

\begin{abstract}
A new fully implicit, time accurate algorithm suitable for chemically reacting, viscous flows in the transonic-tohypersonic regime is described. The method is based on a class of Total Variation Diminishing (TVD) schemes and uses successive Gauss-Seidel relaxation sweeps. The inversion of large matrices is avoided by partitioning the system into reacting and nonreacting parts, but still maintaining a fully coupled interaction. As a result, the matrices that have to be inverted are of the same size as those obtained with the commonly used point implicit methods. In this paper we illustrate the applicability of the new algorithm to hypervelocity unsteady combustion applications. We present a series of numerical simulations of the periodic combustion instabilities observed in ballistic-range experiments of blunt projectiles flying at subdetonative speeds through hydrogen-air mixtures. The computed frequencies of oscillation are in excellent agreement with experimental data.
\end{abstract}

\section{Introduction}

The development of hypersonic propulsion systems requires efficient computational fluid dynamics (CFD) codes to support experimental tests and extrapolate the results to full scale and flight conditions (where static pressures may be an order of magnitude higher than those achievable in experimental facilities). The acquisition of data in hypervelocity facilities is difficult because of the short test times available. In a pulse facility, for example, the duration of the transient test flows is on the order of one millisecond, which may be insufficient for the establishment of the viscous dominated fluid dynamic and chemical reaction processes ${ }^{1}$. In a ram accelerator ${ }^{2}$, there is considerable interest in studying the transient development of the shock-induced combustion process, its stability and interactions with a reacting or nonreacting boundary layer. Due to the highly stretched grids necessary to resolve boundary layers and the high flow velocities involved, simulation of these problems requires a fully implicit time accurate CFD code in order to maintain high computational efficiency. Recent time accurate simulations of hypersonic reacting flows ${ }^{3-5}$ have been conducted predominantly with explicit or point implicit methods, in which only the source term is treated implicitly. The reason is partly due to the fact that the Jacobian matrix associated with the chemistry source terms complicates the solution procedures for the commonly used implicit ADI methods because the governing equations become stiff. Since explicit or point implicit methods are constrained by the CFL condition, they are very inefficient for solving viscous reacting flows.

In the present work, we have developed a new relaxation method that is used with an implicit TVD scheme to solve the fully coupled chemically reacting flow equations. The algorithm is based on successive backward and forward Gauss-Seidel relaxation sweeps. The inversion of large matrices is avoided by partitioning the system into reacting and nonreacting parts, but a fully coupled interaction is still maintained. As a result, the matrices that have to be inverted are of the same size as those obtained with point implicit methods. The method presented is second order accurate in time and space, and allows variable time stepping. The time step is automatically selected based on the satisfaction of a convergence criterion.

The performance of the new method is illustrated by applying it to hypervelocity, unsteady, shock-induced 
combusting flows. We present a series of numerical simulations of the periodic combustion instabilities observed in ballistic-range experiments of blunt projectiles flying at subdetonative speeds through hydrogen-air mixtures.

\section{Numerical Formulation}

\section{Governing Equations}

We consider the nonequilibrium Navier-Stokes equations for two-dimensional or axisymmetric flow, in which the global continuity equation is replaced by species continuity equations. They can be expressed in the following conservation form for a gas mixture containing $n$ species and in general curvilinear coordinates $(\xi, \eta)$

$$
\frac{\partial \mathbf{Q}}{\partial t}+\frac{\partial\left(\mathbf{F}-\mathbf{F}_{v}\right)}{\partial \xi}+\frac{\partial\left(\mathbf{G}-\mathbf{G}_{v}\right)}{\partial \eta}+j\left(\mathbf{S}-\mathbf{S}_{v}\right)=\mathbf{W}
$$

where

$$
\mathbf{Q}=J^{-1}\left[\begin{array}{c}
\rho_{1} \\
\rho_{2} \\
\vdots \\
\rho_{n} \\
\rho u \\
\rho v \\
e
\end{array}\right]
$$

is the vector of dependent variables.

The equations describe two-dimensional flow if $j=0$ and axisymmetric flow if $j=1$. The variables are the mass density of the $i$ th species $\rho_{i}$ (mixture mass density $\rho=\sum_{i=1}^{n} \rho_{i}$ ), the velocity components $u$ and $v$ and the total energy per unit volume $e$. $J$ denotes the grid Jacobian and $F$ and $G$ are the inviscid flux vectors in the $\xi$ and $\eta$ directions respectively. Similarly, $\mathbf{F}_{v}$ and $\mathbf{G}_{v}$ are the viscous fluxes. The terms $S$ and $S_{v}$ are the axisymmetric source terms, and $\mathbf{W}$ is the chemical source term. A detailed description of all the terms appearing in Eq. (1), and of the additional state and constitutive equations needed to close the system are given by Yungster ${ }^{6}$.

\section{Description of the Implicit TVD Scheme}

For simplicity and without loss of generality, the implicit method is presented here for the two-dimensional Euler equations $\left(\mathbf{F}_{v}=\mathbf{G}_{v}=\mathbf{0}\right)$. For the Navier-Stokes equations, a central difference approximation for the viscous fluxes should be added to the right hand side operator, and the corresponding viscous Jacobians should be added to the implicit operator. Let the time step $\Delta t^{n}=t^{n+1}-t^{n}$, and the change $\Delta \mathbf{Q}^{n}=\mathbf{Q}^{n+1}-\mathbf{Q}^{n}$, and define

$$
\Delta=\frac{\Delta t^{n}}{\Delta t^{n-1}}
$$

then a second-order, variable-step backward differentiation formula (BDF) applied to Eq. 1 gives

$$
\begin{aligned}
\Delta \mathbf{Q}_{j, k}^{n}= & \gamma \Delta \mathbf{Q}_{j, k}^{n-1}-\beta \Delta t^{n}\left[\tilde{\mathbf{F}}_{j+\frac{1}{2}, k}-\tilde{\mathbf{F}}_{j-\frac{1}{2}, k}+\right. \\
& \left.\tilde{\mathbf{G}}_{j, k+\frac{1}{2}}-\tilde{\mathbf{G}}_{j, k-\frac{1}{2}}-W_{j, k}\right]^{n+1}
\end{aligned}
$$

where the BDF method coefficients $\gamma$ and $\beta$ are

$$
\begin{aligned}
& \gamma=\frac{\Delta^{2}}{1+2 \Delta} \\
& \beta=\frac{(1+\Delta)}{1+2 \Delta}
\end{aligned}
$$

The function $\tilde{\mathbf{F}}_{j+\frac{1}{2}, k}$ is the numerical flux in the $\xi$ direction evaluated at $\left(j+\frac{1}{2}, k\right)$. It is computed using Yee's second order TVD scheme ${ }^{7}$ as follows. Let $\mathbf{A}=\partial \mathbf{F} / \partial \mathbf{Q}$ and $\mathbf{B}=\partial \mathbf{G} / \partial \mathbf{Q}$. Then, for a pseudo finite volume formulation, the numerical flux can be expressed as

$$
\tilde{\mathbf{F}}_{j+\frac{1}{2}, k}=\frac{1}{2}\left(\mathbf{F}_{j, k}+\mathbf{F}_{j+1, k}+\mathbf{R}_{j+\frac{1}{2}} \boldsymbol{\Phi}_{j+\frac{1}{2}}\right)
$$

In two dimensions, this pseudo finite volume formulation can be made "truly" finite volume by a slight modification in the calculation of some of the metric terms. See Ref. 7 for further details.

Here, $\mathbf{R}_{j+\frac{1}{2}}$ denotes the matrix of eigenvectors of the flux Jacobian matrix $A$ evaluated at some symmetric average of $\mathbf{Q}_{j, k}$ and $\mathbf{Q}_{j+1, k}$, denoted as $\mathbf{Q}_{j+\frac{1}{2}}$. Abgrall's extension of Roe's averaging for real gas mixtures ${ }^{8}$ is used in the present study. Similarly, one can define in this manner the numerical flux in the $\eta$ direction.

The elements, $\phi_{j+\frac{1}{2}}^{l}$, of the dissipation vector $\Phi_{j+\frac{1}{2}}$ are:

$$
\phi_{j+\frac{1}{2}}^{l}=-\Psi\left(a_{j+\frac{1}{2}}^{l}\right)\left[\alpha_{j+\frac{1}{2}}^{l}-\hat{Q}_{j+\frac{1}{2}}^{l}\right]
$$

Here $a_{j+\frac{1}{2}}^{l}$ denotes the eigenvalues of $\mathbf{A}$ evaluated at $\mathbf{Q}_{j+\frac{1}{2}}$, and $\alpha_{j+\frac{1}{2}}^{l}$ denotes the elements of the vector $\alpha_{j+\frac{1}{2}}$ :

$$
\alpha_{j+\frac{1}{2}}=\frac{\mathbf{R}_{j+\frac{1}{2}}^{-1}\left(\mathbf{Q}_{j+1, k} J_{j+1, k}-\mathbf{Q}_{j, k} J_{j, k}\right)}{0.5\left(J_{j+1, k}+J_{j, k}\right)}
$$

The function $\Psi$ is :

$$
\Psi(z)= \begin{cases}|z| & |z| \geq \epsilon \\ \frac{\left(z^{2}+\epsilon^{2}\right)}{2 \epsilon} & |z|<\epsilon\end{cases}
$$

The entropy correction parameter, $\epsilon$, in Eq. (10) is taken to be a function of the velocity and sound speed ${ }^{7}$

$$
\begin{aligned}
\epsilon_{j+\frac{1}{2}}= & \tilde{\epsilon}\left\{\left|U_{j+\frac{1}{2}, k}\right|+\left|V_{j+\frac{1}{2}, k}\right|\right. \\
& \left.+\frac{1}{2}\left[\left(\sqrt{\xi_{x}^{2}+\xi_{y}^{2}}+\sqrt{\eta_{x}^{2}+\eta_{y}^{2}}\right) a\right]_{j+\frac{1}{2}, k}\right\}(11)
\end{aligned}
$$


where $a$ is the frozen sound speed, $U$ and $V$ are the contravariant velocities $\left(U=\xi_{x} u+\xi_{y} v, V=\eta_{x} u+\eta_{y} v\right)$, and $\tilde{\epsilon}$ is a small number in the range $0 \leq \tilde{\epsilon} \leq 0.4$, which controls the convergence rate and the sharpness of discontinuities.

The "limiter" function $\hat{Q}_{j+\frac{1}{2}}$ used in this study is the following:

$\hat{Q}_{j+\frac{1}{2}}^{l}=\operatorname{minmod}\left[2 \alpha_{j-\frac{1}{2}}^{l}, 2 \alpha_{j+\frac{1}{2}}^{l}, 2 \alpha_{j+\frac{3}{2}}^{l}, \frac{1}{2}\left(\alpha_{j-\frac{1}{2}}^{l}+\alpha_{j+\frac{3}{2}}^{l}\right)\right]$

The eigenvalues and eigenvectors of the fully coupled chemically reacting equations, as well as the resulting expressions for $\mathbf{R \Phi}$ are given in Ref. 9.

\section{Iterative Scheme}

Following the work of $\mathrm{Yee}^{10}$, we linearize Eq. 4 in a conservative manner:

$$
\begin{array}{r}
\mathbf{I}+\beta \Delta t^{n}\left[\mathbf{H}_{j+\frac{1}{2}, k}^{\xi}-\mathbf{H}_{j-\frac{1}{2}, k}^{\xi}+\mathbf{H}_{j, k+\frac{1}{2}}^{\eta}-\right. \\
\left.\mathbf{H}_{j, k-\frac{1}{2}}^{\eta}-\mathbf{C}_{j, k}\right]^{n} \mathbf{E}^{n}=-\mathbf{R H S}
\end{array}
$$

where RHS is the right-hand side of Eq. 4, with the exception that the term in square brackets is evaluated at time level $n$ instead of $n+1$. Also

$$
\mathbf{E}^{n}=\mathbf{Q}^{n+1}-\mathbf{Q}^{n}
$$

and

$$
\mathbf{C}=\frac{\partial \mathbf{W}}{\partial \mathbf{Q}}
$$

The remaining terms in Eq. 13 are defined as follows:

$$
\begin{aligned}
& \mathbf{H}_{j+\frac{1}{2}, k}^{\xi}=\frac{1}{2}\left[\mathbf{A}_{j+1, k}-\boldsymbol{\Omega}_{j+\frac{1}{2}, k}^{\xi}\right] \\
& \mathbf{H}_{j, k+\frac{1}{2}}^{\eta}=\frac{1}{2}\left[\mathbf{B}_{j, k+1}-\boldsymbol{\Omega}_{j, k+\frac{1}{2}}^{\eta}\right]
\end{aligned}
$$

where $\Omega$ is defined as

$$
\begin{aligned}
& \boldsymbol{\Omega}_{j+\frac{1}{2}, k}^{\xi}=\mathbf{R}_{j+\frac{1}{2}} \boldsymbol{\Lambda}_{j+\frac{1}{2}}^{\xi} \mathbf{R}_{j+\frac{1}{2}}^{-1} \\
& \boldsymbol{\Omega}_{j, k+\frac{1}{2}}^{\eta}=\mathbf{R}_{k+\frac{1}{2}} \boldsymbol{\Lambda}_{k+\frac{1}{2}}^{\eta} \mathbf{R}_{k+\frac{1}{2}}^{-1}
\end{aligned}
$$

(Here $\mathbf{R}_{k+\frac{1}{2}}$ denotes the matrix of eigenvectors of the flux Jacobian matrix $B$ evaluated at some symmetric average of $\mathbf{Q}_{j, k}$ and $\mathbf{Q}_{j, k+1}$ ). The terms $\Lambda_{j+\frac{1}{2}}^{\xi}$ and $\Lambda_{k+\frac{1}{2}}^{\eta}$ are diagonal matrices defined as

$$
\begin{aligned}
& \Lambda_{j+\frac{1}{2}}^{\xi}=\operatorname{diag}\left[\Psi\left(a_{j+\frac{1}{2}}^{l}\right)\right] \\
& \Lambda_{k+\frac{1}{2}}^{\eta}=\operatorname{diag}\left[\Psi\left(a_{k+\frac{1}{2}}^{l}\right)\right]
\end{aligned}
$$

The nonstandard notation of $\mathrm{Yee}^{7}$ is used. That is

$$
\mathbf{H}_{j+\frac{1}{2}, k}^{\xi} \mathbf{E}^{n}=\frac{1}{2}\left[\mathbf{A}_{j+1, k} \mathbf{E}_{j+1, k}^{n}-\mathbf{\Omega}_{j+\frac{1}{2}, k}^{\xi}\left(\mathbf{E}_{j+1, k}^{n}-\mathbf{E}_{j, k}^{n}\right)\right]
$$

We can rearrange Eq. 13 by defining "plus" and "minus" matrices having nonnegative and nonpositive eigenvalues respectively,

$$
\begin{aligned}
& \mathbf{A}^{+}=\frac{1}{2}\left(\mathbf{A}_{j-1, k}+\boldsymbol{\Omega}_{j-\frac{1}{2}, k}^{\xi}\right) \\
& \mathbf{B}^{+}=\frac{1}{2}\left(\mathbf{B}_{j, k-1}+\boldsymbol{\Omega}_{j, k-\frac{1}{2}}^{\eta}\right) \\
& \mathbf{A}^{-}=\frac{1}{2}\left(\mathbf{A}_{j+1, k}-\boldsymbol{\Omega}_{j+\frac{1}{2}, k}^{\xi}\right) \\
& \mathbf{B}^{-}=\frac{1}{2}\left(\mathbf{B}_{j, k+1}-\boldsymbol{\Omega}_{j, k+\frac{1}{2}}^{\eta}\right)
\end{aligned}
$$

Define the matrix $D$ as

$\beta \Delta t^{n} \mathbf{D}=\mathbf{I}+\beta \Delta t^{n}\left(\boldsymbol{\Omega}_{j+\frac{1}{2}, k}^{\xi}+\boldsymbol{\Omega}_{j-\frac{1}{2}, k}^{\xi}+\boldsymbol{\Omega}_{j, k+\frac{1}{2}}^{\eta}+\boldsymbol{\Omega}_{j, k-\frac{1}{2}}^{\eta}\right)$

Then Eq. 13 reduces to the following expression:

$$
\begin{aligned}
-\mathbf{A}^{+} \mathbf{E}_{j-1, k}^{n} & -\mathbf{B}^{+} \mathbf{E}_{j, k-1}^{n}+(\mathbf{D}-\mathbf{C}) \mathbf{E}_{j, k}^{n}+ \\
\mathbf{A}^{-} \mathbf{E}_{j+1, k}^{n} & +\mathbf{B}^{-} \mathbf{E}_{j, k+1}^{n}=-\frac{\mathbf{R H S}}{\beta \Delta t^{n}}
\end{aligned}
$$

This equation is solved iteratively using a lower-upper relaxation procedure consisting of successive Gauss-Seidel (LU-SGS) sweeps as follows:

Step 1

$$
\begin{aligned}
(\mathbf{D}-\mathbf{C}) \mathbf{E}_{j, k}^{*}= & \mathbf{A}^{+} \mathbf{E}_{j-1, k}^{*}+\mathbf{B}^{+} \mathbf{E}_{j, k-1}^{*}-\frac{\mathbf{R H S}}{\beta \Delta t^{n}}- \\
& \mathbf{A}^{-} \mathbf{E}_{j+1, k}^{(m-1)}-\mathbf{B}^{-} \mathbf{E}_{j, k+1}^{(m-1)}
\end{aligned}
$$

followed by Step 2

$$
\begin{aligned}
(\mathbf{D}-\mathbf{C})\left(\mathbf{E}_{j, k}^{(m)}-\mathbf{E}_{j, k}^{*}\right)= & -\left[\mathbf{A}^{-}\left(\mathbf{E}_{j+1, k}^{(m)}-\mathbf{E}_{j+1, k}^{(m-1)}\right)+\right. \\
& \left.\mathbf{B}^{-}\left(\mathbf{E}_{j, k+1}^{(m)}-\mathbf{E}_{j, k+1}^{(m-1)}\right)\right](30)
\end{aligned}
$$

Here, $(m)$ is the subiteration counter, and we have used the notation

$$
\mathbf{E}^{(m)} \equiv\left(\mathbf{E}^{n}\right)^{(m)}
$$

Note that Eqs. 29 and 30 require only block diagonal matrix inversions - a significant advantage over ADI based methods, which require the solution of block tridiagonal or block pentadiagonal systems. To avoid the inversion of large matrices, we can modify the iterative scheme given in Eqs. 29 and 30 by partitioning the vector $\mathbf{Q}$ and the matrices $\mathbf{D}$ and $\mathbf{C}$ as follows:

$$
\mathbf{Q}=\left[\begin{array}{c}
\mathbf{Q}^{I} \\
\mathbf{Q}^{I I}
\end{array}\right] ; \quad \mathbf{Z} \equiv(\mathbf{D}-\mathbf{C})=\left[\begin{array}{ll}
\mathbf{Z}^{11} & \mathbf{Z}^{12} \\
\mathbf{Z}^{21} & \mathbf{Z}^{22}
\end{array}\right]
$$

Here, $\mathbf{Q}^{I}$ is a vector of length $n_{r}$, where $n_{r}$ is the number of reacting species that participate in the chemical 
reactions. The vector $\mathbf{Q}^{I I}$ includes all the remaining variables. Then, the LU-SGS method given by Eqs. 29 and 30 can be simplified as

Step 1

$$
\begin{aligned}
\mathbf{Z}^{22}\left(\mathbf{E}_{j, k}^{*}\right)^{I I}= & {\left[\mathbf{A}^{+} \mathbf{E}_{j-1, k}^{*}+\mathbf{B}^{+} \mathbf{E}_{j, k-1}^{*}-\frac{\mathbf{R H S}}{\beta \Delta t^{n}}-\right.} \\
& \left.\mathbf{A}^{-} \mathbf{E}_{j+1, k}^{(m-1)}-\mathbf{B}^{-} \mathbf{E}_{j, k+1}^{(m-1)}\right]^{I I}- \\
& \mathbf{Z}^{21}\left(\mathbf{E}_{j, k}^{(m-1)}\right)^{I} \\
\mathbf{Z}^{11}\left(\mathbf{E}_{j, k}^{*}\right)^{I}= & {\left[\mathbf{A}^{+} \mathbf{E}_{j-1, k}^{*}+\mathbf{B}^{+} \mathbf{E}_{j, k-1}^{*}-\frac{\mathbf{R H S}}{\beta \Delta t^{n}}-\right.} \\
& \left.\mathbf{A}^{-} \mathbf{E}_{j+1, k}^{(m-1)}-\mathbf{B}^{-} \mathbf{E}_{j, k+1}^{(m-1)}\right]^{I}- \\
& \mathbf{Z}^{12}\left(\mathbf{E}_{j, k}^{*}\right)^{I I}
\end{aligned}
$$

followed by Step 2

$$
\begin{aligned}
\mathbf{Z}^{22}\left(\mathbf{E}_{j, k}^{(m)}-\mathbf{E}_{j, k}^{*}\right)^{I I}= & -\left[\mathbf{A}^{-}\left(\mathbf{E}_{j+1, k}^{(m)}-\mathbf{E}_{j+1, k}^{(m-1)}\right)+\right. \\
& \left.\mathbf{B}^{-}\left(\mathbf{E}_{j, k+1}^{(m)}-\mathbf{E}_{j, k+1}^{(m-1)}\right)\right]^{I I}- \\
& \mathbf{Z}^{21}\left(\mathbf{E}_{j, k}^{*}-\mathbf{E}_{j, k}^{(m-1)}\right)^{I} \\
\mathbf{Z}^{11}\left(\mathbf{E}_{j, k}^{(m)}-\mathbf{E}_{j, k}^{*}\right)^{I}= & -\left[\mathbf{A}^{-}\left(\mathbf{E}_{j+1, k}^{(m)}-\mathbf{E}_{j+1, k}^{(m-1)}\right)+\right. \\
& \left.\mathbf{B}^{-}\left(\mathbf{E}_{j, k+1}^{(m)}-\mathbf{E}_{j, k+1}^{(m-1)}\right)\right]^{I}- \\
& \mathbf{Z}^{12}\left(\mathbf{E}_{j, k}^{(m)}-\mathbf{E}_{j, k}^{*}\right)^{I I}
\end{aligned}
$$

Therefore, at every grid point and for steps 1 and 2, we solve first a $\left(n+3-n_{r}\right) \times\left(n+3-n_{r}\right)$ system of equations for the "nonreacting" variables (i.e., Eq. 33 in step 1), followed by a solution of a $\left(n_{r}\right) \times\left(n_{r}\right)$ system for the reacting species (Eq. 34), and using the most updated values available for the nonreacting variables. Because the operation count is proportional to $N^{3}$ when solving an $N \times N$ system of equations, this modified iterative scheme is preferred over the unpartitioned scheme given by Eqs. 29 and 30, which requires the solution of $n+$ $3) \times(n+3)$ systems of equations.

The solution of the block system of equations is done by LU-decomposition of the $Z^{11}$ and $Z^{22}$ matrices followed by forward substitution and back substitution. The LUdecomposition is stored at every grid point so that at subsequent iterations only the forward and back substitutions are required.

The iterative process given by Eqs. 33-36 is repeated until convergence is achieved. The procedure can be vectorized by taking sweeps along diagonal directions. That is, for a $\xi-\eta$ rectangular computational domain, step 1 above sweeps the domain from the lower left corner to the upper right corner, and step 2 takes sweeps from the upper right corner back to the lower left corner of the computational domain.

\section{Convergence Test}

The test for iteration convergence is similar to that used in the LSODE code ${ }^{11}$, a solver for initial value problems in ordinary differential equation systems. The test is based on the successive differences $\left(\mathbf{Q}^{(m)}-\mathbf{Q}^{(m-1)}\right)$, as compared with an error weight vector, $E W T_{i}$, defined below. Convergence is said to occur if

$$
\delta_{m} \equiv \sqrt{\frac{1}{n} \sum_{i=1}^{n}\left(\frac{\mathbf{Q}_{i}^{(m)}-\mathbf{Q}_{i}^{(m-1)}}{E W T_{i}}\right)^{2}} \leq C_{L}
$$

at every grid point, where

$$
E W T_{i}=R T O L_{i}\left|\mathbf{Q}_{i}^{(m)}\right|+A T O L_{i} ; \quad i=1, \ldots n
$$

and $R T O L_{i}$ and $A T O L_{i}$ are, respectively, the usersupplied local relative and local absolute error tolerances for the $i^{\text {th }}$ component, and $C_{L}$ is a factor of order one. If convergence is achieved in less than the maximum number of iterations permitted, (iter) $)_{\max }$, then the time step is increase by $5 \%-10 \%$ for the next integration step. If the iterative scheme fails to converge in (iter $)_{\max }$, then the time step is reduced by $20 \%-50 \%$. (Our experience to date suggests use of (iter) $)_{\max }=5$.)

\section{Numerical Simulations}

\section{Description of test problem}

The performance of the new algorithm is demonstrated by a series of numerical simulations of spherical-nosed projectiles fired into hydrogen-air mixtures at subdetonative speeds. Experimental studies of such flows were conducted in the 1960's and early 1970's, most notably by Ruegg and Dorsey ${ }^{12}$, Behrens et al. ${ }^{13}$ and Lehr ${ }^{14,15}$. These experiments indicated that the flow field is highly unstable under a wide range of conditions. Depending on the flow conditions, the periodic instability appears in two main types referred to as "regular regime" and "large-disturbance" regime. In the present paper, we focus on the regular regime characterized by a highly regular, periodic flow structure (see Figs. 3a, 5a and 7a, taken from the work of Lehr ${ }^{14}$ ). A mechanism for the regular regime periodic combustion instability, containing most of the essential features, was first proposed by Toong and coworkers $^{16,17}$. Three important processes form the basis of Toong's model. They are described below, and are schematically illustrated in the one-dimensional diagrams shown in Fig. 1. This one-dimensional analysis could be viewed as representing the flow along the stagnation streamline of the blunt projectile.

(I) A new reaction front generates compression waves, which have been termed "reaction shocks", that travel 
upstream (towards the bow shock) and downstream (towards the body stagnation point) as shown in Fig. 1a. Alpert and Toong ${ }^{17}$ demonstrated that such waves are necessary for mass and momentum conservation. The upstream facing reaction shock eventually must overtake the bow shock, strengthening it and producing a reflected rarefaction wave and a contact discontinuity. The rarefaction wave is very weak and plays no role in the instability mechanism. It is usually neglected.

(II) Across the contact discontinuity, which marks the boundary of the gas which has passed through the reinforced bow shock, there is a sharp increase in temperature. The induction time in the hot gas is shortened and as a result, a new reaction front is created between the bow shock and the original reaction front, as shown in Fig $1 b$. This new reaction front generates a pair of reaction shocks as discussed in (I). The reacted gas behind the new reaction front eventually reaches the location of the original reaction front. The latter is extinguished because no more unreacted gas is present. When a reaction front is extinguished, it must be accompanied by the generation of upstream and downstream rarefaction waves which have a strength comparable to the reaction shocks ${ }^{17}$.

(III) The rarefaction wave generated by the extinguishing of the original reaction front eventually overtakes the bow shock. As the rarefaction wave penetrates the bow shock, a fan of weak pressure waves are reflected and a zone of decreasing temperature is created (Fig. 1c). As a result, the ignition delay progressively increases and the reaction front recedes towards the body.

The above processes form the basis of the instability mechanism. The complete cycle can be explained, based on these processes, in a $x$-t diagram as shown in Figure 2. This figure shows the McVey-Toong mechanism ${ }^{16}$, with the addition of the reflected shocks from the body. The importance of these reflected shocks has been recognized only recently, following the computational studies of Wilson and Sussman ${ }^{3}$, and Matsuo et al. ${ }^{4}$. The $x$-t diagram of Fig. 2 shows a particular case for which the reflected shock from the body overtakes the bow shock at exactly the same time as the reaction shock does (resonant mode). In general, this will not be the case and the diagram will become more complex. The cycle of events can be described as follows: A reaction shock and a reflected shock overtake the bow shock simultaneously, strengthening it and reflecting a contact discontinuity and a weak rarefaction wave not shown. A zone of decreasing temperature follows the contact discontinuity, due to a rarefaction wave penetrating the bow shock. The origin of this rarefaction wave is explained below. The hot gas behind the contact discontinuity begins to react creating a new reaction front and a pair of reaction shocks moving upstream (towards the bow shock), and downstream (towards the body). When the contact discontinuity reaches the original reaction front at a later time, it extinguishes it and generates a pair of rarefaction waves. The new reaction front gradually recedes due to the zone of decreasing temperature until it reaches its original location. When the reaction shock (and the reflected shock) overtake the bow shock, a new cycle will begin.

The computation of the periodic combustion instabilities in exothermic blunt body flows represents an excellent test problem, because the numerical method must be able to accurately resolve all the complex wave interactions previously described. The numerical simulation of ballistic range experiments of projectiles fired into detonable mixtures can be traced to the work of Yungster et al. ${ }^{18,19}$, Lee \& Deiwert ${ }^{20}$, Wilson \& MacCormack ${ }^{21}$, and Soetrisno \& Imlay ${ }^{22}$. These studies focused on the cases that exhibited stable combustion. Numerical simulations of the pulsating shock-induced combustion flows were first reported by Wilson and Sussman ${ }^{3}$. Subsequent studies have been conducted by Matsuo et al. ${ }^{4}$, Ahuja \& Tiwari ${ }^{5}$ and by Hosangadi et al. ${ }^{23}$. There are substantial differences in the results predicted by these authors (such as frequency and amplitude of the oscillations) even though all studies were based on similar combustion models. These differences indicate that the problem may be quite sensitive not only to the reaction mechanism used, but also to the numerics and grid used. The work of Wilson and Sussman was based on a flux-vector splitting or upwind TVD point implicit scheme (i.e., the convective terms were treated explicitly whereas the source term was treated implicitly), and utilized the logarithmic transformation of the species conservation equations. Matsuo et al. utilized a point implicit TVD scheme, Ahuja \& Tiwari utilized the SPARK2D code based on MacCormack's scheme with added artificial dissipation. The study of Hosangadi et al. was conducted using the CRAFT code which has an implicit Roe/TVD based upwind formulation with ADI factorization.

\section{Results and Discussion}

A numerical simulation of Lehr's ${ }^{14,15}$ ballistic range experiments is presented. These consisted of sphericalnosed projectiles having a diameter of $15-\mathrm{mm}$ fired into a premixed, stoichiometric mixture of hydrogen-air. The pressure and temperature of the gas mixture was 320 torr and $293 \mathrm{~K}$ respectively for all the cases considered. The Chapman-Jouguet detonation Mach number for this mixture is $M_{C J}=5.10$. The combustion model used in the present study is based on the Jachimowski ${ }^{24}$ mechanism excluding the nitrogen reactions. This mechanism is identical to the one used by Matsuo et al. ${ }^{4}$, and is given in Table 1. The calculations were carried out on a $220 \times 220$ uniform grid, and viscous effects were neglected. The periodic instabilities have been experimentally observed 
only for subdetonative speeds, i.e., for Mach numbers below $M_{C J}$. Computational results are presented for three Mach number flows, $M=4.18,4.48$ and 4.79.

Figure 3 shows instantaneous density, pressure and water mass fraction contours for the $M=4.18$ case. For comparison, the experimental shadowgraph image of Lehr ${ }^{15}$ is also shown in Fig. 3. The water mass fraction contour plot (Fig. 3d) indicates the boundary of the reaction front. The density contour shows the relatively large induction zone separating the bow shock and the combustion front. The large induction time in this case, produces a low pulsating frequency with only one visible pulse in the nose region of the projectile. This prediction agrees with the experimental result shown in Fig. 3a. Figure 3b also shows clearly the contact discontinuity emanating from the edge of the reaction front pulse and moving towards the bow shock. The fact that this wave constitutes a contact discontinuity can be deduced by its absence from the pressure contour plot (Fig. 3c).

The history of density and pressure along the stagnation streamline can be plotted in an $x-t$ diagram corresponding to that in Fig 2. The computed $x-t$ diagram for the $M=4.18$ case is presented in Fig 4 . This figure shows two pulses in the reaction front. The creation of new reaction fronts as well as reaction shocks and the contact discontinuity can be clearly identified in the density plot. This plot shows also the existence of multiple, weak waves reflecting from the projectile surface and bow shock. The presense of these weak waves can be explained by the lack of synchronization between the reaction shock moving towards the bow shock and the reflected shock from the projectile surface.

Table 2 shows the frequency of oscillation reported in the experimental work of $\mathrm{Lehr}^{15}$, compared with the results obtained in the present study and previous computations. The frequency of oscillation predicted in the present work for the $M=4.18$ case is $163 \mathrm{KHz}$, which is in excellent agreement with both the experimental value of $148 \mathrm{KHz}^{15}$ and the computational result of Matsuo et al. ${ }^{4}$, who predicted a frequency of $160 \mathrm{KHz}$.

At higher Mach number flows, the frequency of oscillation will increase, because, as seen from Fig 2, the period of one oscillation is the time required for a reaction shock to overtake the bow shock plus the time required for the contact discontinuity to convect from the bow shock to the new reaction front (i.e. the induction time). The higher the Mach number is, the higher the temperature behind the bow shock, and the shorter the induction time.

Figure 5 shows instantaneous density, pressure, and water mass fraction contours, and the corresponding shadowgraph experimental image for a Mach number flow of $M=4.48$. The shadowgraph picture for this case was obtained with a camera located at a $12^{\circ}$ angle from the perpendicular direction. Four pulses can be clearly iden- tified. A contact discontinuity emanating from each of the pulses is clearly visible in the density plot (Fig. 5b). The pressure plot (Fig. 5c) shows also a pair of reaction shocks, one moving towards the bow shock and the other towards the projectile surface. The fact that no reaction shocks are observed downstream indicates that the instability mechanism is driven primarily by the interactions occurring in a small region near the stagnation point. The $\mathrm{H}_{2} \mathrm{O}$ mass fraction contour plot in Fig. $5 \mathrm{~d}$ confirms the formation of the new reaction fronts.

A typical calculation required approximately 4000 steps and $7.5 \mathrm{hrs}$ of CPU time on a CRAY-C90. The number of subiterations (iter) $\max$ was 5 , and the maximum CFL number varied from 2 to 5 approximately.

The history of density and pressure along the stagnation streamline is plotted in Fig. 6. Note that for this condition the wave interaction is almost perfectly synchronized (resonant mode), that is, the reflected shock from the body overtakes the bow shock almost at the same time as the reaction shock. This situation corresponds exactly to the schematic wave diagram of Fig. 2. The near perfect synchronization between the reflected shock and the reaction shock produces a very clean wave pattern of nearly constant frequency and amplitude. The frequency predicted by the present calculation is $431 \mathrm{KHz}$ and the flow is exactly periodic. This is in excellent agreement to the reported experimental frequency of oscillation of $425 \mathrm{KHz}^{15}$.

The final calculation considered a Mach number of $M=4.79$. Figure 7 presents instantaneous density, pressure, and water mass fraction contours, as well as the experimental shadowgraph image (obtained from a perpendicular direction as in Fig. 3a). The reaction front is much closer to the bow shock, and therefore the frequency of the oscillation is higher. Figure 8 shows the history of density and pressure along the stagnation streamline. Note that in this case the reflected shock overtakes the bow shock after two periods of oscillation (second resonant mode). However, the reaction shock and the reflected shock are not perfectly synchronized as in the previous case. As a result, the wave structure is not as clean as for the $M=4.48$ case, and the frequency and amplitude of the pulses is not exactly constant. The predicted frequency of oscillation varied from 701 to $716 \mathrm{KHz}$. This result is also in very good agreement with the experimental frequency of $720 \mathrm{KHz}^{15}$, and with the computational result of Matsuo et al. ${ }^{4}$, who predicted a frequency of $725 \mathrm{KHz}$. The computation of Matsuo et al. predicted an exactly second resonant mode. This case was also computed by Wilson and Sussman ${ }^{3}$ and Hosangadi et al. ${ }^{23}$. The former predicted a frequency of oscillation of $530 \mathrm{KHz}$, and the latter a frequency in the $450-500 \mathrm{KHz}$ range, both significantly lower than those obtained in the present study and by Matsuo et al. and Lehr ${ }^{15}$. One possible cause 
for the discrepancy in the results of Hosangadi et al., is the reaction mechanism. Their study utilized a simpler 7 -species model that may not be accurate enough. The study of Wilson and Sussman included 13 nitrogen reactions in addition to the reactions considered in the present study (and in Matsuo's work). To test the effects of the nitrogen reactions, we conducted static ignition studies of stoichiometric hydrogen-air mixtures at the postshock conditions, with and without the nitrogen reactions considered by Wilson and Sussman. Our results showed that, for the conditions considered, the nitrogen reactions have no effect on the ignition delay, rate of heat release or equilibrium temperature. Therefore, the difference in the results cannot be attributed to the reaction model.

Finally, it is interesting to compare the stagnation pressure variation as a function of time for the three cases studied. This comparison is shown in Fig. 9. Note that for the nearly resonant $M=4.48$ case the pressure pattern repeats itself almost identically. Also, the amplitude of the oscillation is much larger than the other two cases as a result of the reinforcing, synchronized action of the reaction and reflected shocks. In the $M=4.79$ case one can notice the change in the pressure pattern as a result of the lack of synchronization. Also, there is a larger variation in the amplitude of the oscillations. The average pressure level increases with Mach number as expected.

\section{Conclusions}

A new time-accurate algorithm suitable for chemically reacting flows in the transonic-to-hypersonic regime was presented. The salient features of the new method are: 1) fully implicit, fully coupled scheme; 2) second-order accurate in time and space; 3 ) automatic time-step selection; and 4) an efficient iterative scheme that avoids the inversion of large matrices.

Numerical simulations of periodic combustion instabilities observed in ballistic range experiments indicate that the new method can accurately and efficiently solve complex, unsteady, chemically reacting flows.

\section{Acknowledgments}

This work was supported in part by the Numerical Aerodynamic Simulation Program (NAS).

\section{References}

[1] Rogers, R.C., Workshop on the Application of Pulse Facilities to Hypervelocity Combustion Simulation," NASP Workshop Publication 1008, Aug. 1990.

[2] Hertzberg, A., Bruckner, A.P. and Knowlen, C., "Experimental Investigation of Ram Accelerator Propulsion Modes," Shock Wave International Journal, Vol. 1, No. $1,1991$.
[3] Wilson, G.J. and Sussman, M.A., "Computation of Unsteady Shock-Induced Combustion Using Logarithmic Species Conservation Equations," AIAA Journal, Vol. 31, No. 2, February 1993.

[4] Matsuo, A., Fujiwara, T. and Fuji, K., "Flow Features of Shock-Induced Combustion Around Projectile Traveling at Hypervelocities," AIAA Paper 93-0451, January 1993.

[5] Ahuja, J.K. and Tiwari, S.N., "A Parametric Study of Shock-Induced Combustion in a Hydrogen-Air System," AIAA Paper 94-0674, January 1994.

[6] Yungster, S., "Numerical Study of Shock-Wave Boundary Layer Interactions in Premixed Combustible Gases," AIAA Journal, Vol. 30, No. 10, October 1992, pp. 23792387.

[7] Yee, H.C., Klopfer, G.H. and Montagnè, J.-L., "HighResolution Shock-Capturing Schemes for Inviscid and Viscous Hypersonic Flows," NASA TM-100097, Apr. 1988.

[8] Abgrall, R., "Extension of Roe's Approximate Riemann Solver to Equilibrium and Nonequilibrium Flows," Proceedings of the 8th GAMM-Conference on Numerical Methods in Fluid Mechanics, Delft, Netherlands, Sept. 27-29, 1989.

[9] Yungster, S., Eberhardt, S. and Bruckner, A.P., "Numerical Simulation of Hypervelocity Projectiles in Detonable Gases," AIAA Journal, Vol. 29, No. 2, February 1991, pp. 187-199.

[10] Yee, H.C., "Construction of Explicit and Implicit Symmetric TVD Schemes and Their Applications," Journal of Computational Physics, Vol. 68, 1987, pp. 151-179. [11] Radhakrishnan, K. and Hindmarsh, A.C., "Description and Use of LSODE, the Livermore Solver for Ordinary Differential Equations," NASA RP-1327, Lawrence Livermore National Laboratory Report UCRLID-113855, Dec. 1993.

[12] Ruegg, F.W. and Dorsey, W.W., "A Missile Technique for the Study of Detonation Waves," Journal of Research of the National Bureau of Standards, Vol. 66, No. 1, January 1962, pp. 51-58.

[13] Behrens, H., Struth, W., and Wecken, F., "ShockInduced Combustion by High-Speed Shots in Explosive Gas Mixtures," Institute Saint Louis (ISL) Report 4/67, Saint Louis, France, October 1967.

[14] Lehr, H.F., "Experiments on Shock-Induced Combustion," Acta Astronautica, Vol. 17, Nos. 4 \& 5, 1972, pp. 589-596.

[15] Lehr, H.F., "Experimente Zur Stossinduzierten Verbrennung in Wasserstoff/Luft - und Wasserstoff/Sauerstoff- Gemischen," Institute Saint Louis (ISL) Report 20/71, Saint Louis, France, July 1971, (Dissertation, Karlsruhe 1971).

[16] McVey, J.B. and Toong, T.Y., "Mechanism of Instabilities of Exothermic Hypersonic Blunt-Body Flows," 
Combustion Science and Technology, Vol. 3, No. 2, 1971, pp. 63-76.

[17] Alpert, R.L. and Toong, T.Y., "Periodicity in Exothermic Hypersonic Flows About Blunt Projectiles," Astronautica Acta, Vol. 17, Nos. 4 \& 5, 1972, pp. 539560.

[18] Yungster, S., Eberhardt, S. and Bruckner, A.P., "Numerical Simulation of Shock-Induced Combustion Generated by High-Speed Projectiles in Detonable Gas Mixtures," AIAA Paper 89-067, January 1989.

[19] Yungster, S., Eberhardt, S. and Bruckner, A.P., "Numerical Simulation of Hypervelocity Projectiles in Detonable Gases," AIAA Journal, Vol. 29, No. 2, February 1991, pp. 187-199.

[20] Lee, S. and Deiwert, G.S., "Flux-Vector Splitting Calculation of Nonequilibrium Hydrogen-Air Reactions," Journal of Spacecraft, Vol. 27, No. 2, March-April 1990. [21] Wilson, G.J. and MacCormack, R.W., "Modeling Supersonic Combustion Using a Fully-Implicit Numerical Method," AIAA Paper 90-2307, July 1990.

[22] Soetrisno, M. and Imlay, S.T., "Simulation of the Flow Field of a Ram Accelerator," AIAA Paper 91-1915, June 1991.

[23] Hosangadi, A., York, B.J., Sinha, N. and Dash, S.M., "Progress in Transient Interior Ballistic Flowfield Simulations Using Multi-Dimensional Upwind/Implicit Numerics," AIAA Paper 93-1915, June 1993.

[24] Jachimowski, C.J., "An Analytical Study of the Hydrogen-Air Reaction Mechanism with Application to Scramjet Combustion," NASA TP-2791, February 1988.
Table 1: $H_{2}$-air reaction mechanism ${ }^{a}$

\begin{tabular}{|c|c|c|c|c|}
\hline No. & Reaction & $\bar{A}$ & $\bar{\theta}$ & $\bar{b}$ \\
\hline$\overline{1}$ & $\overline{\mathrm{H}_{2}+\mathrm{O}_{2}} \rightleftharpoons \mathrm{BO}_{2}+\bar{H}$ & $1.00 \times 10^{14}$ & 28197.38 & 0.0 \\
\hline 2 & $\mathrm{H}+\mathrm{O}_{2} \rightleftharpoons \mathrm{OH}+\mathrm{O}$ & $2.60 \times 10^{14}$ & 8459.21 & 0.0 \\
\hline 3 & $\mathrm{H}_{2}+\mathrm{O} \rightleftharpoons \mathrm{OH}+\mathrm{H}$ & $1.80 \times 10^{10}$ & 4481.37 & 1.0 \\
\hline 4 & $\mathrm{H}_{2}+\mathrm{OH} \rightleftharpoons \mathrm{H}+\mathrm{H}_{2} \mathrm{O}$ & $2.20 \times 10^{13}$ & 2593.15 & 0.0 \\
\hline 5 & $\mathrm{OH}+\mathrm{OH} \rightleftharpoons \mathrm{O}+\mathrm{H}_{2} \mathrm{O}$ & $6.30 \times 10^{12}$ & 548.84 & 0.0 \\
\hline 6 & $\mathrm{H}+\mathrm{OH}+\mathrm{M} \rightleftharpoons \mathrm{H}_{2} \mathrm{O}+\mathrm{M}$ & $2.20 \times 10^{22}$ & 0.0 & -2.0 \\
\hline 7 & $H+H+M \rightleftharpoons H_{2}+M$ & $6.40 \times 10^{17}$ & 0.0 & -1.0 \\
\hline 8 & $H+O+M \rightleftharpoons O H+M$ & $6.00 \times 10^{16}$ & 0.0 & -0.6 \\
\hline 9 & $\bar{H}+\mathrm{O}_{2}+M \rightleftharpoons \mathrm{H} \mathrm{O}_{2}+M$ & $2.10 \times 10^{15}$ & -503.52 & 0.0 \\
\hline 10 & $\bar{O}+O+M \rightleftharpoons O_{2}+M$ & $6.00 \times 10^{13}$ & -906.34 & 0.0 \\
\hline 11 & $\mathrm{HO}_{2}+\mathrm{H} \rightleftharpoons \mathrm{OH}+\mathrm{OH}$ & $1.40 \times 10^{24}$ & 543.81 & 0.0 \\
\hline 12 & $\mathrm{HO}_{2}+\mathrm{H} \rightleftharpoons \mathrm{H}_{2} \mathrm{O}+\mathrm{O}$ & $1.00 \times 10^{13}$ & 543.81 & 0.0 \\
\hline 13 & $\mathrm{HO}_{2}+\mathrm{O} \rightleftharpoons \mathrm{O}_{2}+\mathrm{OH}$ & $1.50 \times 10^{13}$ & 478.35 & 0.0 \\
\hline 14 & $\mathrm{HO}_{2}+\mathrm{OH} \rightleftharpoons \mathrm{H}_{2} \mathrm{O}+\mathrm{O}_{2}$ & $8.00 \times 10^{12}$ & 0.0 & 0.0 \\
\hline 15 & $\mathrm{HO}_{2}+\mathrm{HO}_{2} \rightleftharpoons \mathrm{H}_{2} \mathrm{O}_{2}+\mathrm{O}_{2}$ & $2.00 \times 10^{12}$ & 0.0 & 0.0 \\
\hline 16 & $\mathrm{H}+\mathrm{H}_{2} \mathrm{O}_{2} \rightleftharpoons \mathrm{H}_{2}+\mathrm{H} \mathrm{O}_{2}$ & $1.40 \times 10^{12}$ & 1812.69 & 0.0 \\
\hline 17 & $\mathrm{O}+\mathrm{H}_{2} \mathrm{O}_{2} \rightleftharpoons \overline{\mathrm{OH}}+\mathrm{HO}_{2}$ & $1.40 \times 10^{13}$ & 3222.56 & 0.0 \\
\hline 18 & $\mathrm{OH}+\mathrm{H}_{2} \mathrm{O}_{2} \rightleftharpoons \mathrm{H}_{2} \mathrm{O}+\mathrm{HO}_{2}$ & $6.10 \times 10^{12}$ & 720.04 & 0.0 \\
\hline 19 & $\mathrm{H}_{2} \mathrm{O}_{2}+\mathrm{M} \rightleftharpoons \mathrm{OH}+\mathrm{OH}+\mathrm{M}$ & $1.20 \times 10^{17}$ & 22910.37 & $\mathbf{0 . 0}$ \\
\hline
\end{tabular}

a Forward rate coefficient $k_{f}=A T^{b} \exp (-\Theta / T)$; units are moles, seconds, centimeters, and Kelvins.

Third-body efficiencies:

(6) $\mathrm{H}_{2} \mathrm{O}=6.0$

(7) $\mathrm{H}_{2} \mathrm{O}=6.0, \mathrm{H}_{2}=2.0$

(8) $\mathrm{H}_{2} \mathrm{O}=5.0$

(9) $\mathrm{H}_{2} \mathrm{O}=16.0, \mathrm{H}_{2}=2.0$

(19) $\mathrm{H}_{2} \mathrm{O}=15.0$

Table 2: Frequency of Oscillation ( $\mathrm{KHz})$

\begin{tabular}{|c|c|c|c|}
\hline & $\mathrm{M}=4.18$ & $\mathrm{M}=4.48$ & $\mathrm{M}=4.79$ \\
\hline Experiment $^{15}$ & 148 & 425 & 720 \\
\hline Present method & 163 & 431 & $701-716$ \\
\hline Matsuo et al.* & 160 & - & 725 \\
\hline Wilson \& Sussman ${ }^{3}$ & - & - & 530 \\
\hline Hosangadi et al. ${ }^{23}$ & - & $=$ & $450-500$ \\
\hline
\end{tabular}




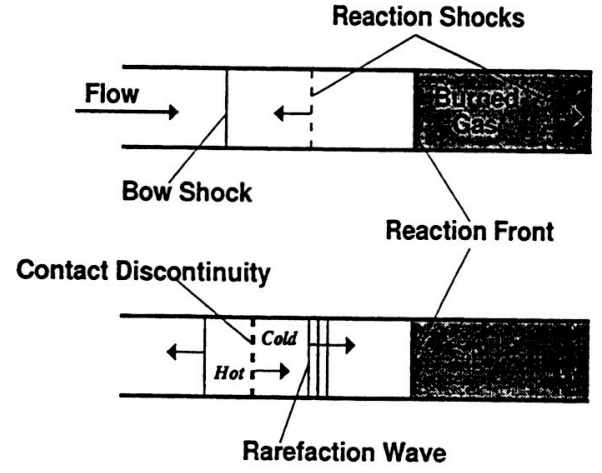

(a)

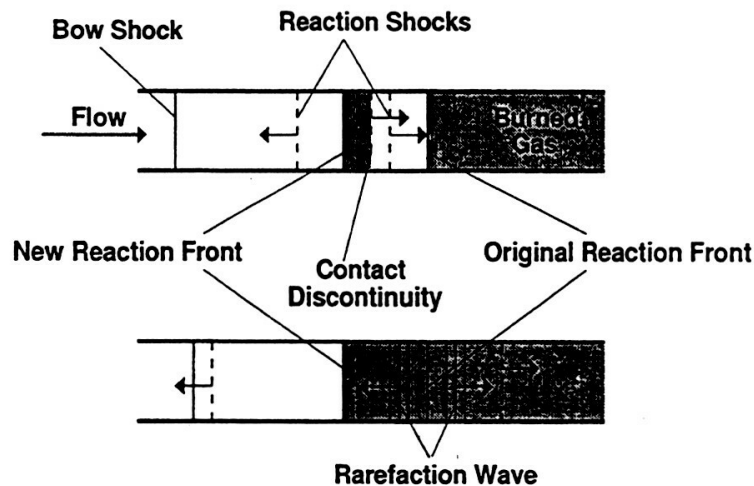

(b)

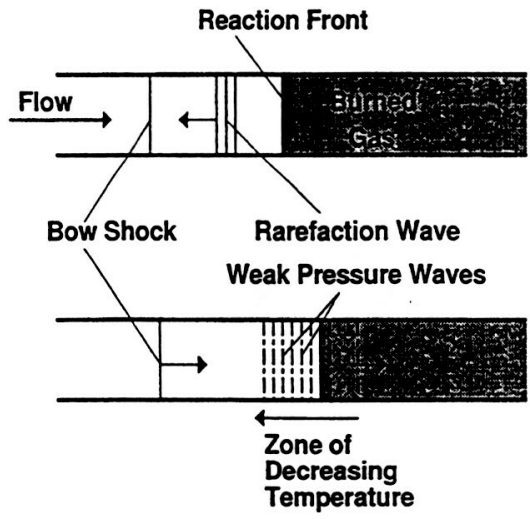

(c)

Figure 1. Schematic diagram of one dimensional wave interactions: (a) generation of reaction shocks and interaction with bow shock; (b) initiation of new reaction front, and extinguishment of original reaction front; (c) interaction of rarefaction wave with the bow shock.

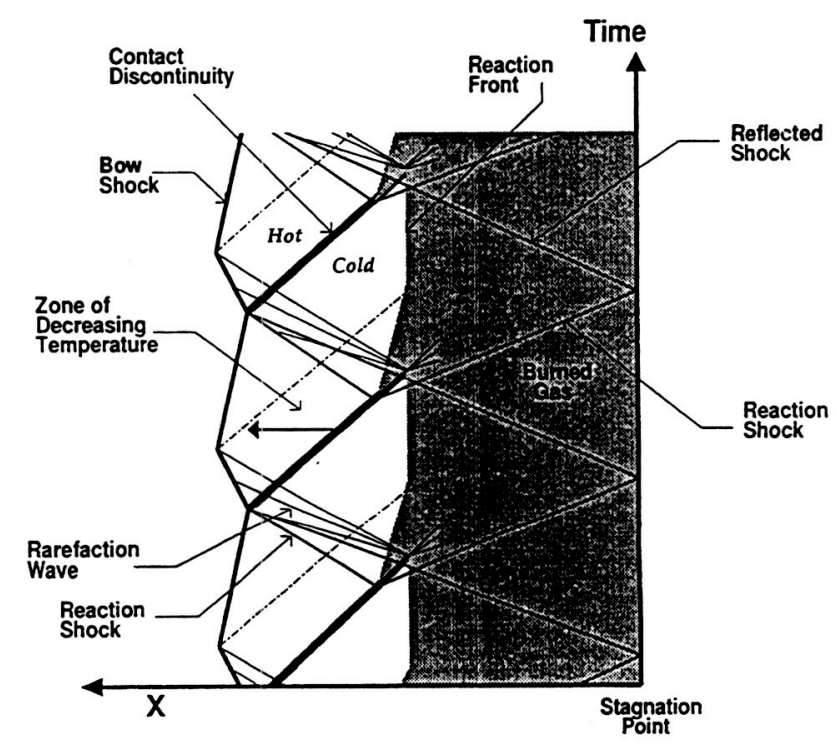

Figure 2. McVey and Tong ${ }^{16} \mathrm{x}$-t diagram along the stagnation streamline. 


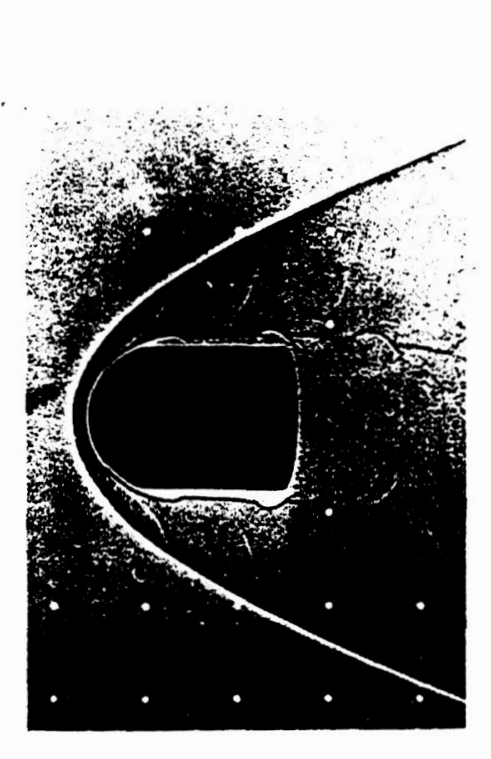

(a)

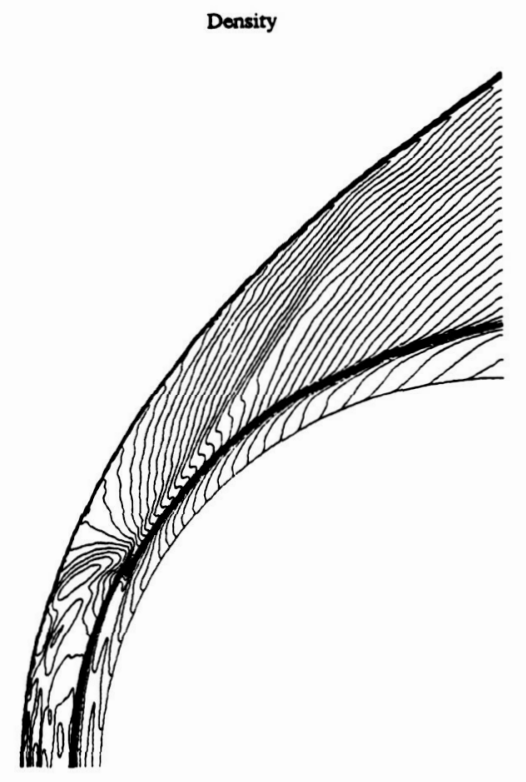

(b)

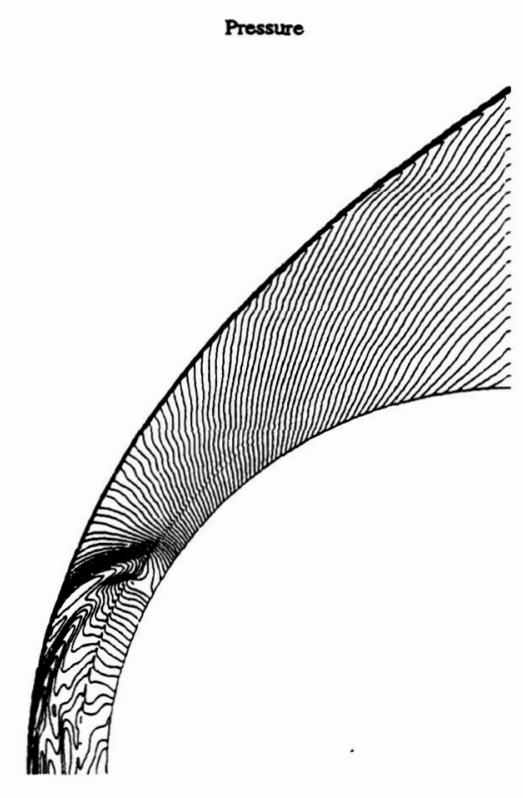

(c) (d)

Figure 3. Experimental and computational results for a projectile moving at $M=4.18$ in a stoichiometric mixture of hydrogen-air: (a) experimental shadowgraph image $\left(\operatorname{Lehr}^{15}\right) ;(\mathrm{b})$ density $\left(\rho / \rho_{\infty}\right)$, contour range: $(\min =.25, \max =5.35$, inc $=.1) ;(\mathrm{c})$ pressure $\left(p / p_{\infty}\right),(1.5,23.0, .25) ;(\mathrm{d}) \mathrm{H}_{2} \mathrm{O}$ mass fraction, $(.005, .22, .005)$. 


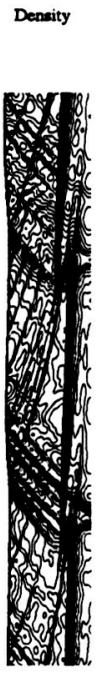

Pressure

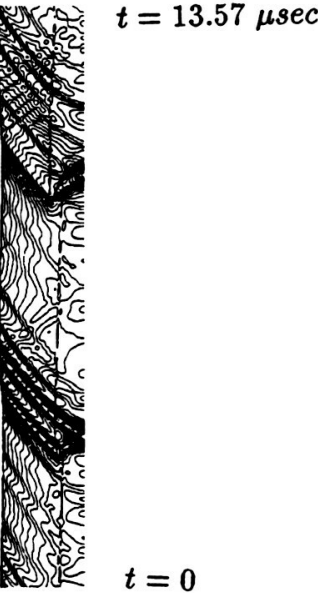

(a)

(b)

Figure 4. History of density and pressure along the stagnation streamline; $M=4.18$ : (a) density $\left(\rho / \rho_{\infty}\right)$, contour range: $(\min =2.5, \max =5.85$, inc $=.05) ;(\mathrm{b})$ pressure $\left(p / p_{\infty}\right),(18.0,28.1, .25)$.

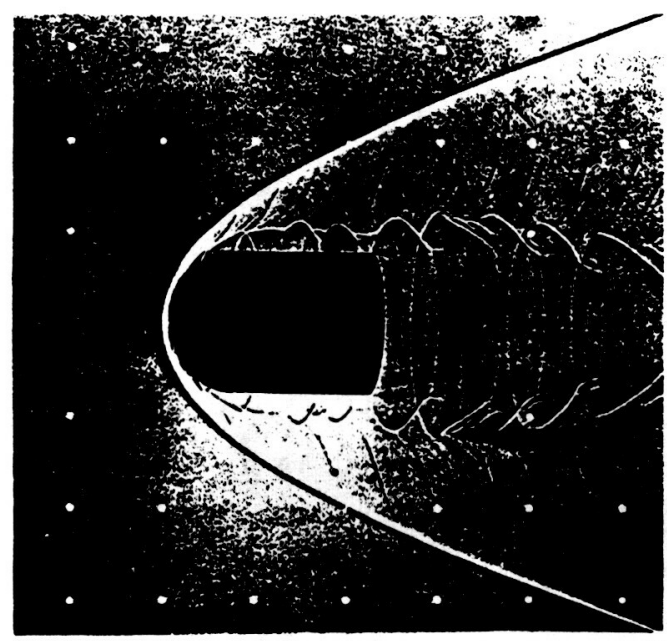

(a)

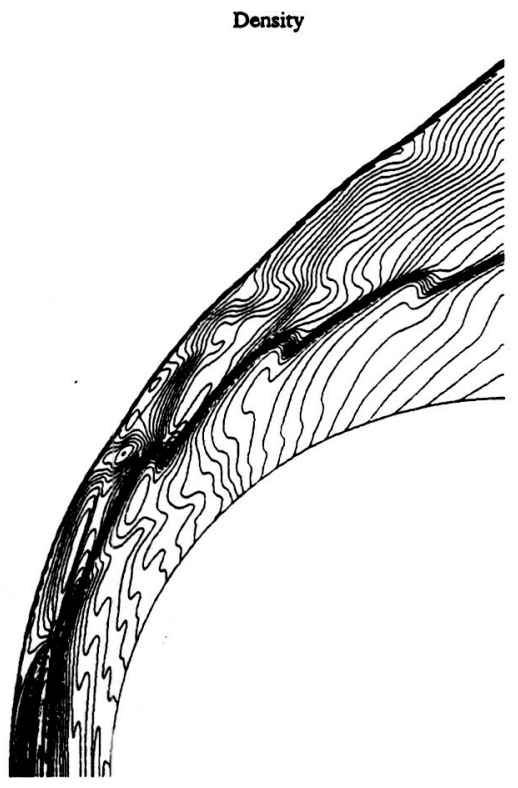

(b)

Figure 5. Experimental and computational results for a projectile moving at $M=4.48$ in a stoichiometric mixture of hydrogen-air: (a) experimental shadowgraph image ( $\mathrm{Lehr}^{15}$ ) taken at a $12^{\circ}$ angle from the perpendicular direction; (b) density $\left(\rho / \rho_{\infty}\right)$, contour range: $(\min =.35, \max =6.35$, inc $=.1)$. 


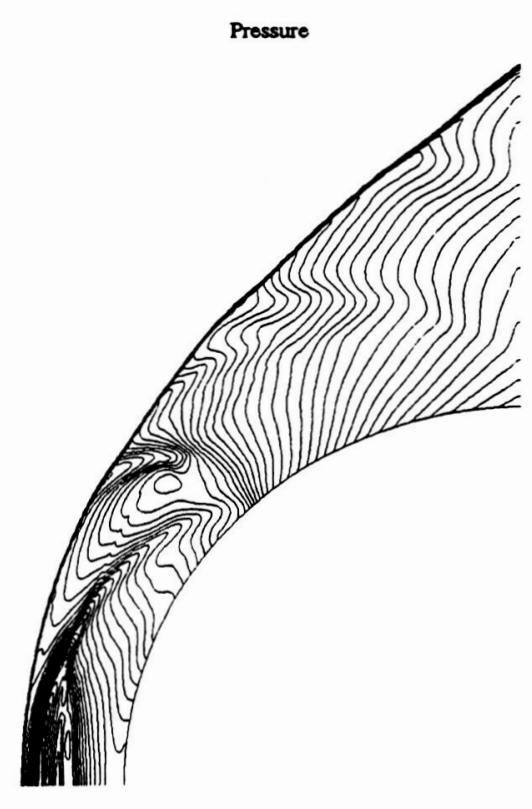

(c)

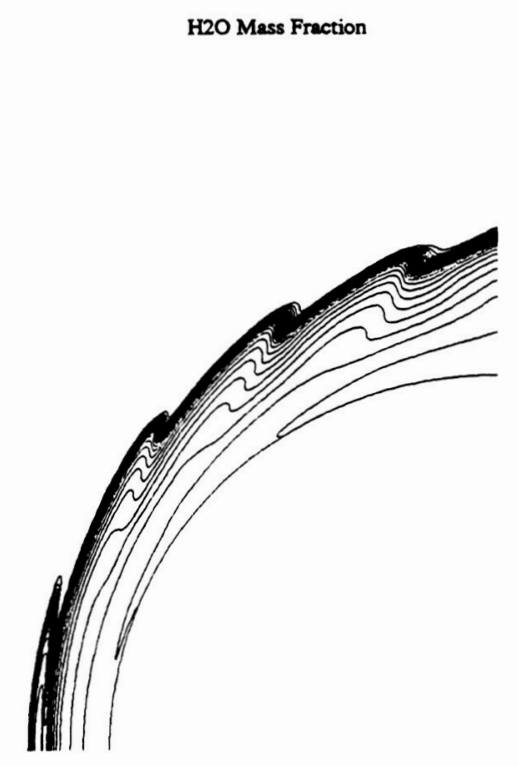

(d)

Figure 5. continued: (c) pressure $\left(p / p_{\infty}\right)$, contour range: $(\min =.75, \max =31.75$, inc $=.5)$; (d) $\mathrm{H}_{2} \mathrm{O}$ mass fraction, $(.005, .22, .005)$.

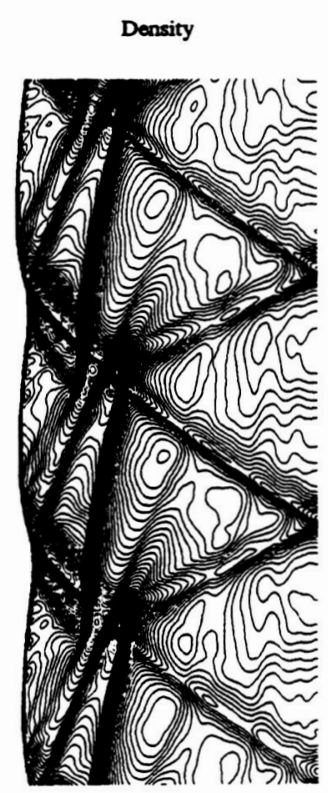

(a)

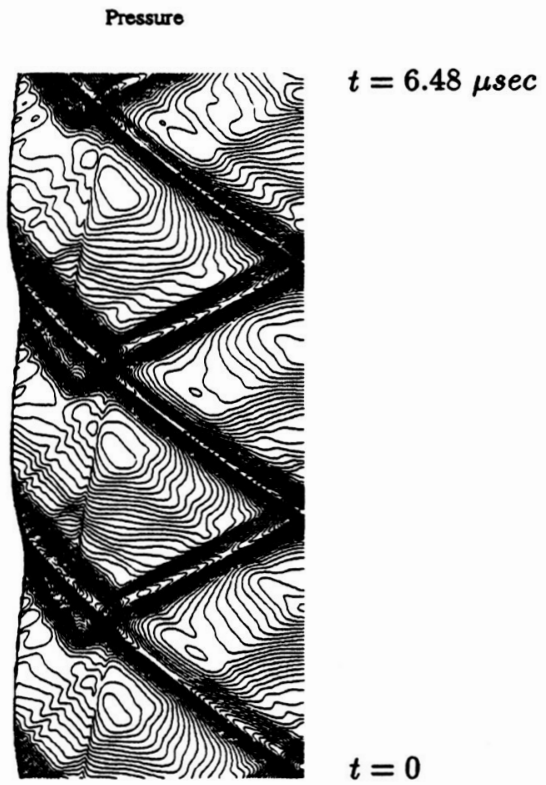

(b)

Figure 6. History of density and pressure along the stagnation streamline; $M=4.48$ : (a) density $\left(\rho / \rho_{\infty}\right)$, contour range: $(\min =2.5, \max =6.6$, inc $=.05)$; (b) pressure $\left(p / p_{\infty}\right),(20.0,34.5, .25)$. 


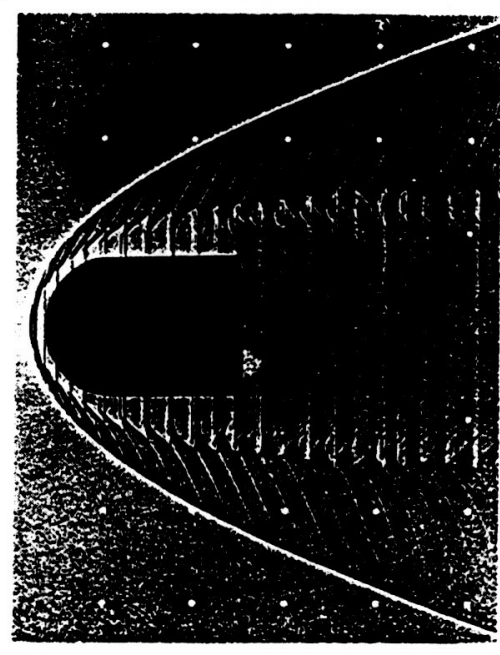

(a)

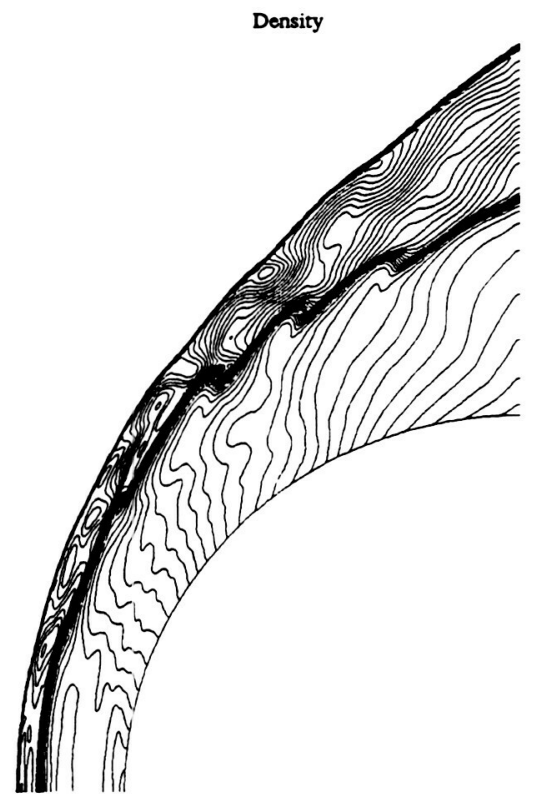

(b)

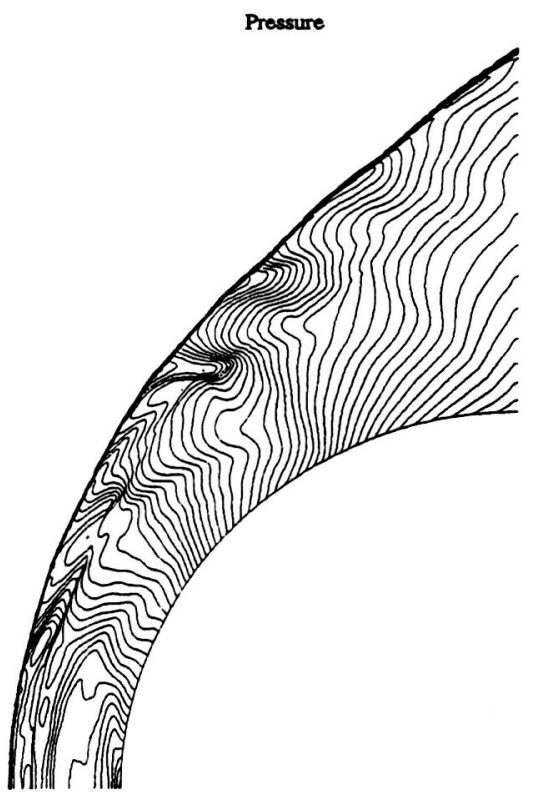

(c)

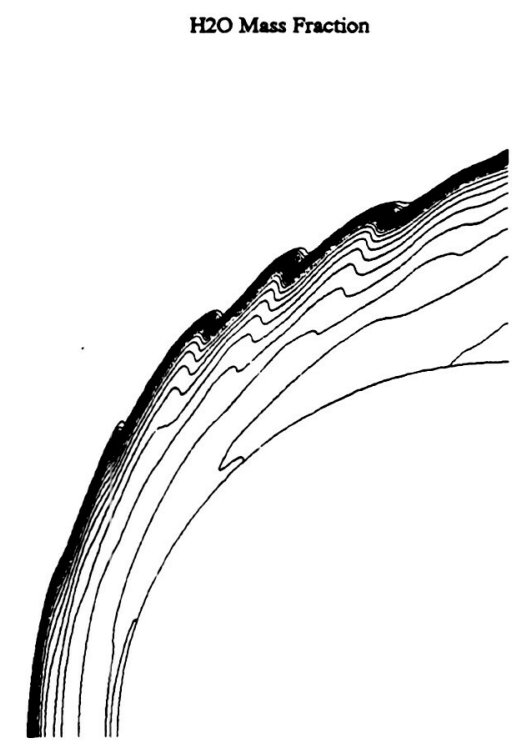

(d)

Figure 7. Experimental and computational results for a projectile moving at $M=4.79$ in a stoichiometric mixture of hydrogen-air: (a) experimental shadowgraph image $\left(\operatorname{Lehr}^{15}\right)$; (b) density $\left(\rho / \rho_{\infty}\right)$, contour range: $(\min =.35, \max =5.65$, inc $=.1)$; (c) pressure $\left(p / p_{\infty}\right),(.75,30.75, .5)$; (d) $\mathrm{H}_{2} \mathrm{O}$ mass fraction, $(.005, .225, .005)$. 


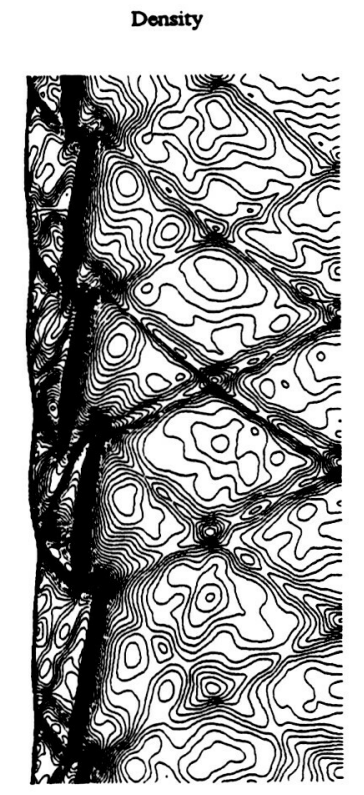

(a)

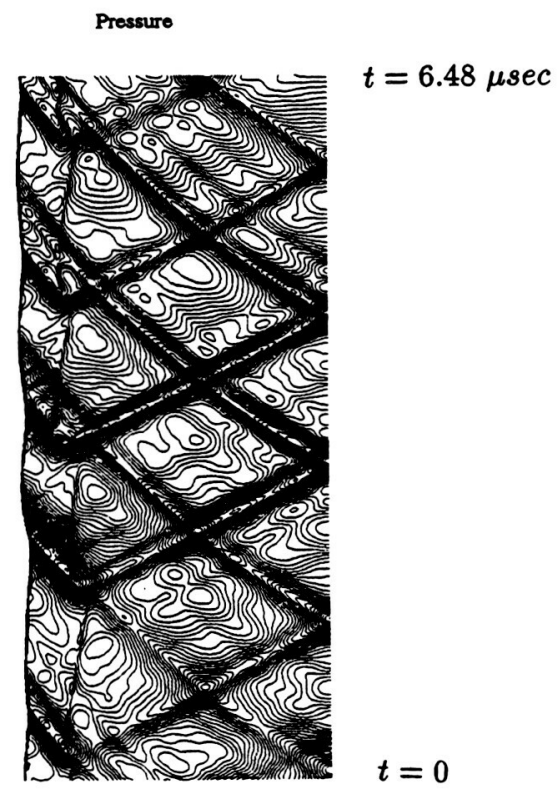

(b)

Figure 8. History of density and pressure along the stagnation streamline; $M=4.79$ : (a) density $\left(\rho / \rho_{\infty}\right)$, contour range: $(\min =2.5, \max =6.5$, inc $=.05) ;(\mathrm{b})$ pressure $\left(p / p_{\infty}\right),(20.0,35.25, .25)$.

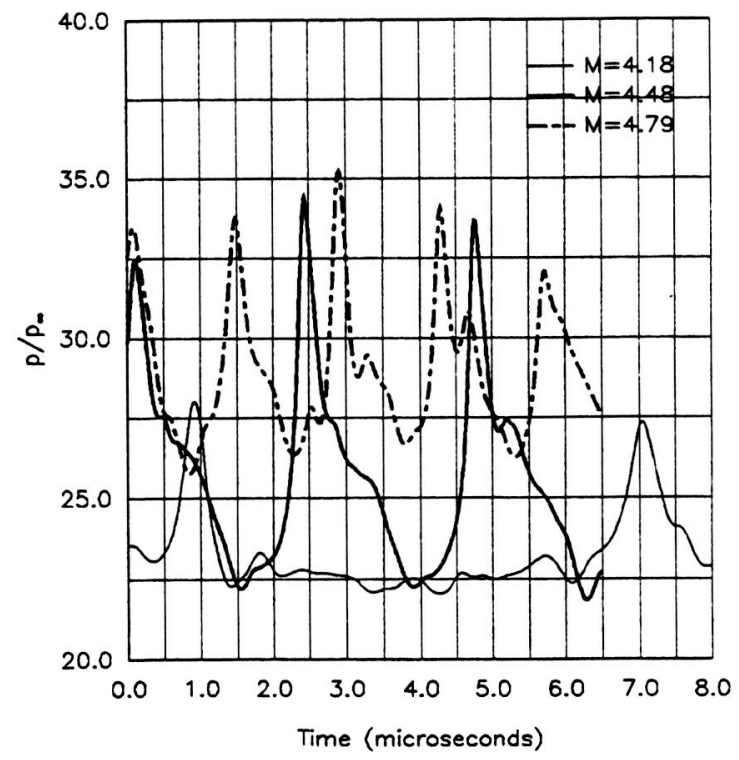

Figure 9. Stagnation point pressure history for three Mach numbers. 
Public reporting burden for this collection of inlormation is estimated to average 1 hour per response, including the time for reviewing instructions, searching existing data sources, gathering and maintaining the data needed, and completing and reviewing the collection of information. Send comments regarding this burden estimate or any other aspect of this Davis Highway, Suite 1204, Arlington, VA 22202-4302, and to the Office of Management and Budget, Paperwork Reduction Project (0704-0188), Washington, DC 20503.

\begin{tabular}{|l|c|r|}
\hline 1. AGENCY USE ONLY (Leave blank) & $\begin{array}{r}\text { 2. AEPORT DATE } \\
\text { August } 1994\end{array}$ & $\begin{array}{r}\text { 3. REPORT TYPE AND DATES COVERED } \\
\text { Technical Memorandum }\end{array}$ \\
\hline
\end{tabular}

\section{TITLE AND SUBTITLE}

5. FUNDING NUMBERS

A Fully Implicit Time Accurate Method for Hypersonic Combustion: Application to Shock-Induced Combustion Instability

6. AUTHOR(S)

$$
\text { WU-505-90-5K }
$$

Shaye Yungster and Krishnan Radhakrishnan

\section{PERFORMING ORGANIZATION NAME(S) AND ADDRESS(ES)}

National Aeronautics and Space Administration

Lewis Research Center

Cleveland, Ohio 44135-3191

\section{SPONSORINGMONITORING AGENCY NAME(S) AND ADDRESS(ES)}

National Aeronautics and Space Administration

Washington, D.C. 20546-0001
8. PERForming ORgANIZATION REPORT NUMBER

E-9069

10. SPONSORINGMONITORING AGENCY REPORT NUMBER

NASA TM-106707

ICOMP-94-18

AIAA-94-2965

\section{SUPPLEMENTARY NOTES}

Prepared for the 30th Joint Propulsion Conference cosponsored by AIAA, ASME, SAE, and ASEE, Indianapolis, Indiana, June 27-29, 1994. Shaye Yungster, Institute for Computational Mechanics in Propulsion, NASA Lewis Research Center (work funded by NASA Cooperative Agreement NCC3-233); Krishnan Radhakrishnan, NYMA, Inc., 2001 Aerospace Parkway, Brook Park, Ohio 44142 (work funded by NASA Contract NAS3-27186). ICOMP Program Director, Louis A. Povinelli, organization code 2600, (216) 433-5818.

12a. DISTRIBUTIONAVAILABILITY STATEMENT 12b. DISTRIBUTION CODE

Unclassified - Unlimited

Subject Category 34

\section{ABSTRACT (Maximum 200 mords)}

A new fully implicit, time accurate algorithm suitable for chemically reacting, viscous flows in the transonic-to-hypersonic regime is described. The method is based on a class of Total Variation Diminishing (TVD) schemes and uses successive Gauss-Seidel relaxation sweeps. The inversion of large matrices is avoided by partitioning the system into reacting and nonreacting parts, but still maintaining a fully coupled interaction. As a result, the matrices that have to be inverted are of the same size as those obtained with the commonly used point implicit methods. In this paper we illustrate the applicability of the new algorithm to hypervelocity unsteady combustion applications. We present a series of numerical simulations of the periodic combustion instabilities observed in ballistic-range experiments of blunt projectiles flying at subdetonative speeds through hydrogen-air mixtures. The computed frequencies of oscillation are in excellent agreement with experimental data.

\section{SUBJECT TERMS}

TVD scheme; Relaxation method; Hypersonic combustion; Shock-induced combustion instability

17. SECURITY CLASSIFICATION
OF REPORT

Unclassified

18. SECURITY CLASSIFICATION
OF THIS PAGE
Unclassified

Unclassified
19. SECURITY CLASSIFICATION OF ABSTRACT Unclassified
15. NUMBER OF PAGES

16

16. PRICE CODE

$\mathrm{A03}$

20. LIMITATION OF ABSTRACT 